\title{
Intramuros e extramuros: a aventura do conhecimento!
}

\author{
Roseli Fígaro \\ Professora doutora na Escola de Comunicações e Artes da Universidade de São Paulo, com \\ pós-doutorado na Universidade de Provence, França. Autora dos livros: Relações de comuni- \\ cação no mundo do trabalho; Na cena paulista: o teatro amador. Circuito alternativo \\ e popular de cultura (1927-1945); Comunicação e trabalho: estudo de recepção. Pes- \\ quisadora do grupo de pesquisa do Arquivo Miroel Silveira e do grupo de pesquisa Comunica- \\ ção e Trabalho ECA-USP/CNPq. \\ E-mail: figaro@uol.com.br
}

\begin{abstract}
Resumo: Nas escolas, desconsideram-se tanto o poder da língua como sua forma de conteúdo e de expressão das relações sociais. Fato muito bem exemplificado pelo filme francês Entre os muros da escola, baseado no livro homônimo de François Bégaudeau. Não compreender o papel da língua leva a definir a comunicação como transmissão de informação, desqualificando o processo de interação entre sujeitos na construção de sentidos. Tema que também pode ser depreendido na análise do filme do inglês Danny Boyle, Quem quer ser um milionário? O protagonista do filme, o jovem Jamal, torna-se um ganhador porque passa a associar as palavras-chave apresentadas como respostas do jogo do milhão a fatos de sua experiência pessoal. As palavras não têm significado pelo que representam no jogo, mas porque remetem a sua vida. Ambos os filmes são excelentes exemplos para o estudo da recepção da comunicação e podem ser fontes de conhecimento a professores e alunos em sala de aula.
\end{abstract}

Palavras-chave: língua, recepção, comunicação, Quem quer ser um milionário?, Entre os muros da escola.
Abstract: The power of the language, the fact that it is the body of content and the way of expression of social relations are usually disregarded in school. These issues are well exemplified in the French motion picture Entre les Murs (The Class), by François Bégaudeau. The nonunderstanding of the role of language leads to the definition of communication as information transmission, disqualifying the process of interaction among subjects in the sense construction. This issue can also be gathered in the analysis of the British motion picture directed by Danny Boyle, Slumdog Millionaire. The protagonist, the young man Jamal, becomes the winner of a million quiz show because he understands the keywords that are introduced to him as anwers to the questions as clues to remind him facts of his personal experience. The words do not have significance because they are introduced as the quiz answers, but because they remind him of his own life. Both pictures are excellent examples for the study of the communication reception and they can be knowledge sources for teachers and students in classroom.

Keywords: language, reception, communication, Slumdog Millionaire, Entre les Murs.

É frequente ouvir que o professor levou um filminho para os alunos assistirem porque estava querendo folga! Esta é uma questão que se reproduz mesmo entre professores. Tratá-la, demanda enfrentar algumas discussões. A 
comunicação \& educação • Ano XIV • Número 2 • maio/ago 2009

1. A revista Comunicação \& Educação publica, desde seu primeiro número, a seção Videografia, escrita pela Profa. Dra. Maria Ignês Carlos Magno. Cada uma das edições da revista apresenta nesta seção um projeto de trabalho pedagógico com filmes em sala de aula.

2. BAKHTIN, Mikhail. Marxismo e filosofia da linguagem. São Paulo: Hucitec, 1988. cap. VI. mais elementar delas pode ser pontuada com a seguinte afirmação: utilizar o audiovisual em sala de aula ${ }^{1}$ é uma prática que requer conhecimento bastante sólido do conteúdo que se trabalha na ocasião com os alunos, bem como de informações sobre o filme e as possibilidades que ele traz como linguagem e como texto diferenciado a ser explorado.

Nesse sentido, não se trata de passar um filminho, mas de ousar recorrer a discursos não escolares para dar novo tratamento aos temas curriculares. $\mathrm{E}$ talvez esse seja o ponto fraco da escola hoje: a existência de assuntos tratados em sala que não se sabe para que servem. Atrelado a isso, vale discutir se o filme tem ou não valor como experiência expressiva que propicia aos alunos outra maneira de receber informações e buscar conhecimento.

Há filmes, inclusive, que podem gerar excelente oportunidade para se trabalhar com os professores. Mais do que instrumentalizá-los com recursos pedagógicos para serem utilizados em sala de aula, podem servir para questionar valores, reavaliar métodos e compreender processos de conhecimento. Este é o objetivo que se discute neste artigo a partir de dois filmes.

Em 2009, as salas de cinema receberam duas obras cinematográficas importantes e premiadas. A primeira, Entre os muros da escola - filme francês de Laurent Cantet, adaptado do livro homônimo de François Bégaudeau, que também atua como ator principal, e encenado por alunos sem nenhuma experiência como atores -, recebeu o prêmio de Cannes como melhor filme de 2008, foi indicado ao Oscar de melhor filme estrangeiro e venceu o prêmio Lumière de melhor filme. A segunda, Quem quer ser um milionário? - dirigido em 2008 pelo inglês Danny Boyle e totalmente filmado na Índia -, ganhou oito Oscars, inclusive o de melhor filme. Foi inspirado no livro de Vikas Swarup, Sua resposta vale um bilhão. Traz referências à vida cotidiana da população pobre, sobretudo das crianças indianas. Pode ser lido, também, como uma homenagem à Bollywood, a indústria cinematográfica de Mumbai. Ambos dão oportunidade de o receptor discutir aspectos do processo de recepção que têm a ver com a produção de conhecimento.

\section{A LÍNGUA, A NORMA E A FALA}

O filme Entre os muros da escola questiona o discurso pedagógico do professor e a hierarquia de poder desse discurso. Há uma tensão constante entre professor e aluno, a qual aumenta quando o mestre sente que sua autoridade pode ser rebatida. As perguntas e os problemas que os alunos vão apresentando tratam da identidade - os franceses e os não franceses; ter nascido na França e não ser reconhecido nem se sentir francês. Este aspecto aparece, principalmente, no uso que fazem da língua e ao questionarem sobre a norma culta ser a única correta e verdadeira.

A língua é índice de poder. Ela revela a trajetória da experiência da vida intelectual de um falante. Como signo que se constitui e se atualiza na interação verbal ${ }^{2}$, demanda e remete à densidade da história e da cultura de uma comunidade. Produto das relações humanas numa dada organização social, a 
Intramuros e extramuros: a aventura do conhecimento! - Roseli Fígaro

relação língua/sociedade permite identificar as variações e variedades de uma mesma língua em situação real de fala. Nessa acepção, a língua é matéria da vida, das relações sociais e, assim sendo, é dinâmica, mudancista, afeita aos trancos e barrancos do cotidiano. Há, portanto, numa mesma língua, muitas línguas, ou, como Saramago diz em seu depoimento ao filme Lingua: vidas em português, de Victor Lopes, "não há uma língua portuguesa, mas línguas em português"3.

Talvez se possa parafrasear Saramago para afirmar que Entre os muros da escola quer mostrar que o Velho Continente se renova com outras identidades, outras culturas que trazem às línguas nacionais a tensão que a sociedade tradicional e o poder hegemônico não admitem. A batalha que se dá entre os muros da escola é uma disputa pelos significados, pela fala, pelo direito de enunciar a partir de um dado de realidade que o poder escolar instituído não reconhece. Se o permite, é sempre de forma simulada, de acordo com padrões estabelecidos pelas normas que regulamentam, por exemplo, no caso do filme, o Conselho de Escola, o qual avalia e julga o desempenho dos alunos. A fala do banlieue não é permitida, não tem tradução, nem permissão para entrar na escola. Mas ela está lá com seus falantes. Quando o professor é questionado sobre por que e para que aprendem uma língua que não falam, que não usam (o subjuntivo pretérito), a resposta fica aquém do necessário. O professor limita-se a reafirmar a exigência de se aprender o francês-padrão, bem como reconhecer que, algumas vezes, o seu uso pode parecer pedante, esnobe. Ou, como mais bem definido pelo personagem do aluno: é a fala do burguês! O professor não está preparado para encarar o processo de ensino/aprendizado como propõe Paulo Freire, no clássico Pedagogia do oprimido ${ }^{4}$, partindo da realidade do aluno e levando-o ao contato com outras realidades, sem preconceitos e sem menosprezar a experiência de cada um.

A norma culta da língua é uma maneira de expressão e depende da situação de enunciação. Portanto, nem o subjuntivo pretérito do francês é pedante e inútil, como também não o são as formas verbais e o vocabulário da norma popular do dialeto popular. Faltou ao professor do filme explicar ao aluno, curioso e corretamente contestador, a obrigatoriedade do uso de uma norma, a importância de se transitar pelos diferentes níveis de fala, de capacitar-se para o exercício da diglossia e de, portanto, dominar as diferentes normas da língua que circulam na sociedade, como sinônimo de poder. O papel da língua é a comunicação; regular seu funcionamento é atribuição dos falantes na sociedade. Entre grupos e culturas tão diferentes, num mesmo espaço urbano, é mais do que natural que haja variedades, configurando dialetos os quais constituem normas da língua e permitem a comunicação entre os membros de uma mesma comunidade linguística.

$\mathrm{O}$ professor errou porque não permitiu ao aluno saber que o uso de seu dialeto, a fala do banlieue, tem valor, pois possibilita a comunicação e a expressão das particularidades de seu grupo social. No entanto, isso não basta! A vida na sociedade contemporânea é complexa e coloca em contato identidades diferenciadas, o que requer conhecimento e transmissão de outros dialetos sociais, inclusive o dialeto culto, portador do status de padrão correto da língua.
3. LÍNGUA: vidas em Português. Direção: Victor Lopes. Brasil/Portugal: TV Zero/Sambascope/Costa do Castelo, 2004. 1 DVD (105 min).

4. FREIRE, Paulo. Pedagogia do oprimido. 17. ed. Rio de Janeiro: Paz e Terra, 1987. 
comunicação \& educação • Ano XIV • Número 2 • maio/ago 2009

5. SCHAFF, Adam. Linguagem e conhecimento. Coimbra: Almedina, 1974.

6. BACCEGA, Maria Aparecida. Do mundo editado à edição do mundo. Comunicação \& Educação São Paulo: Moderna, $\mathrm{n}$ v. 1, 1995. Disponível em: <http://revcom2. portcom.intercom.org. br/index.php/Comedu/ article/view/3867/3631> Acesso em: 17 jun. 2009.
O correto também é relativo: correto em que situação de fala, em intercâmbio com quais grupos e para manifestar quais expressões e interesses? Ou seja, o que se pretende ressaltar da análise da prática pedagógica ilustrada pelo filme é que a escola, como instituição de regulação, de organização das informações, a partir de determinado ponto de vista, está sendo contestada.

Não se trata de negar a necessidade de os currículos escolares estarem voltados ao conteúdo. Muito ao contrário. Trata-se de enfrentar a falsa dicotomia entre transmitir o conhecimento já construído e construir o conhecimento junto com. Visto que o conhecimento, como bem define Adam Schaff ${ }^{5}$, é a condição de transformar a informação a partir da própria experiência. $\mathrm{O}$ conhecimento é o pensamento particularmente qualificado, ou seja, é o produto da descrição (fatos e suas correlações) da realidade. Está relacionado com a vida concreta objetiva e a condição de abstração e generalização do pensamento. Condição essa a ser adquirida na escola, ao se aclararem para os alunos os porquês e a quais valores passarão a ser investidos ao terem acesso à norma culta e aos demais conteúdos relativos a cada período escolar. Isso posto, pode-se passar adiante, afirmando, como Schaff, que a língua é um aprendizado e uma experiência adquirida na sociedade e em suas instituições.

Esta reflexão que o filme permite deveria ser o mote de discussões entre os profissionais da educação: a negação do aluno em considerar ou não o ensino do francês culto não é um problema de indisciplina; é uma questão de poder!

Outro tema a que remete o filme diz respeito à identidade. A grande maioria dos alunos representados pertence a famílias provenientes de diferentes países da África e da Ásia. São várias etnias e diversos grupos sociais que também têm dificuldades em se reconhecer mutuamente. De comum, possuem o fato de não serem considerados franceses e de residirem em locais que os identificam e os estigmatizam. Para tratar dessa questão, no filme, o professor propõe a redação do autorretrato. A polêmica se dá porque ele exige que cada um se revele. Para quê? Por que dizer de si para os outros? Eles expressam sentimentos de baixa autoestima. O melhor resultado que o professor obtém é do aluno mais rebelde, Souleymane. No laboratório de informática, o jovem utiliza os recursos do computador para enunciar o discurso sobre si mesmo a partir da combinação da linguagem verbal e da não verbal, compondo imagens e legendas que retratam pessoas de sua família, os colegas da escola e a si próprio, destacando seu corpo: rosto, braço, tatuagem no ombro; lugar de inscrição de um discurso, primeiro elemento que o introduz na cena por meio da palavra.

$\mathrm{O}$ acerto do professor na maneira de encaminhar e valorizar a produção daquele aluno é um exemplo de como as diferentes linguagens estão na escola. O uso do computador, da máquina fotográfica e o processo de composição e de edição mobilizam a experiência que vem de fora em proveito de novos conteúdos a serem adquiridos. Souleymane aprende a legendar, a dar voz a cada foto que organiza, compondo o discurso sobre si e sobre os outros que fazem parte de seu mundo. Ele está trilhando o processo de criação editorial. Chegou a vez de ele propor e não apenas receber o mundo que lhe chega editado ${ }^{6}$, não só pelo livro escolar, mas sobretudo pelos meios de comunicação. 
Intramuros e extramuros: a aventura do conhecimento! - Roseli Fígaro

E esse é o gancho para se discutir com os professores o processo de recepção e, por que não dizer, de como as informações que circulam nos discursos da sociedade fazem sentido para cada um de nós.

\section{UM EXEMPLO DO PROCESSO DE RECEPÇÃO}

O filme Quem quer ser um milionário? mostra o cotidiano de um jovem indiano, nascido na maior favela de Mumbai, que, depois de perder a mãe, ser explorado por traficantes de crianças e chegar ao emprego de servente de chá numa empresa de telemarketing, vira celebridade ao participar e ganhar o prêmio máximo num programa de perguntas e respostas na TV. Ele dizia nada saber, mas foi respondendo corretamente, uma a uma, as questões que lhe foram feitas pelo apresentador.

A cada resposta, tem-se um trecho da história da vida de Jamal. Tal qual o conto das mil e uma noites, sua narrativa vai revelando um ponto de vista totalmente oposto ao do ambiente do auditório de TV e ao do tema da pergunta que lhe é feita. As perguntas e as alternativas de resposta são enunciadas pelo apresentador do programa. São como pistas para o jovem puxar da memória a solução, que ele não sabe se é certa, porém que funciona como palavra-chave para rever sua vida. Por exemplo, a resposta correta do nome de um cantor famoso é obtida a partir de um dos nomes apresentados, o qual o faz lembrar de sua infância na favela. $\mathrm{O}$ nome do cantor passa a ter sentido porque o liga à lição de coragem e de força de vontade que aprendeu em um determinado dia. Ou então o nome do presidente norte-americano, cuja imagem está na nota de cem dólares, que lhe vem à memória não porque saiba a resposta certa, mas porque o nome remete-o a uma experiência de dor, desespero e tristeza com um velho amigo, que pede esmolas sob as garras dos exploradores de crianças.

Para Jamal, jovem apaixonado por Latika, as respostas não são certas ou erradas porque dizem respeito à cultura de massa da indústria cultural, da qual originam as perguntas do programa. Para ele, são palavras que têm outros sentidos, estão numa trama maior, dizem respeito a experiências de vida. Elas entram em sintonia com ele pelo valor que possuem no diálogo de momentos específicos da sua vida, de seu irmão e de seus amigos.

O filme pode ser lido como um bom exemplo do que se discute sobre os processos de mediação cultural nos estudos de recepção dos meios de comunicação. A experiência cultural de cada sujeito em seu grupo, mobilizando seus interesses e objetivos, vivendo o dia a dia, relacionando-se com os dados de uma experiência anterior em relação aos gêneros, aos suportes midiáticos, às instituições e aos universos da família, do trabalho, do bairro, da escola, prepara o cenário para a produção de sentidos. A cultura de massa da indústria cultural, exemplificada no programa de auditório do jogo do milhão, tem sentido para Jamal porque é a partir dela que pode reencontrar Latika, sua amada.

O filme de Danny Boyle revela o que tão bem nos explica Jesús Martín-Barbero em Dos meios às mediações ${ }^{7}$. As palavras-chave que provocam a memória,
7. MARTÍN-BARBERO, Jesús. Dos meios às mediações: comunicação, cultura e hegemonia. Rio de Janeiro: UFRJ, 1997. 
comunicação \& educação • Ano XIV • Número 2 • maio/ago 2009

a desafiam e a revelam exatamente porque fazem sentido. Têm sentido porque passam pela mediação das práticas cotidianas da vida do jovem Jamal. Estão inseridas em um contexto que dialogam com a experiência pessoal.

Por que os conteúdos tratados na escola passariam por processos de recepção diferenciados? Como ganham sentido para os jovens alunos as informações obtidas das diferentes áreas de conhecimento? Como captar de Jamal a estratégia para dar a resposta certa? A experiência concreta de vida dos alunos não fica do lado de fora da escola. Conectar os conteúdos escolares ao interesse dos jovens estudantes pressupõe entendê-los como produtores de discursos, em que selecionam, categorizam e organizam, a partir de suas experiências, todos os enunciados que lhes são dirigidos.

\section{ARTIGOS NACIONAIS}

Neste número de Comunicação \& Educação, a seção Artigos Nacionais traz contribuições a partir de diferentes abordagens teóricas e temáticas pertinentes ao campo da Educomunicação.

O primeiro deles, Organizadores da cultura: delimitação e formação, de Antonio Albino Canelas Rubim e Lindinalva Rubim, trata de como as políticas culturais são temas peculiares da contemporaneidade, pois demandam diferentes compreensões do papel do Estado. Este é um assunto de pouca tradição entre nós e tem requerido maiores estudos. Nesse sentido, o artigo traz uma contribuição expressiva, uma vez que os autores discutem a relação entre o sistema cultural e a demanda de novos profissionais para a área da cultura, bem como analisam a necessidade de configuração de uma área de atuação profissional capaz de abarcar os diferentes aspectos envolvidos nessa demanda.

Os meios de comunicação nas novas dinâmicas do aprendizado chamam a atenção para as diferentes dimensões de tempo e de materialidade da escola pública na elaboração dos programas educacionais, comprometidos com a inclusão social. Este é o assunto do artigo de Ercio Sena, Novas tecnologias da comunicação: tempos e materialidade da escola pública.

No artigo Comunicação e educação: atualização da inteligência coletiva em salas de aula, Maria Ogécia Drigo discute, a partir do conceito de inteligência coletiva de Pierre Lévy e da semiótica perciana, a compreensão dos processos de significação na sala de aula.

Acir Dias da Silva e Deise Ellen Piatti realizam, em Traduções poéticas: o Romance d'A Pedra do Reino e o Príncipe do Sangue do Vai-e-Volta, um estudo acerca da tradução que Ariano Suassuna fez das tradições do mundo ibérico para sua obra e como o diretor de televisão Luiz Fernando Carvalho releu esses livros para a microssérie televisiva, veiculada pela Rede Globo, em 2007.

Direitos humanos, cidadania e liberdade de expressão, artigo de Maria Cristina Castilho Costa, retoma a importância do tema quarenta anos após o Ato Institucional número 5 - AI-5, decretado em dezembro de 1968, pela ditadura militar que censurou, assassinou e instituiu o terror em nosso país. A escola 
Intramuros e extramuros: a aventura do conhecimento! - Roseli Fígaro

deveria ser a guardiã da liberdade de expressão, defendendo os direitos humanos e a cidadania, pois sem eles as noções de aprendizagem, de ciência e de conhecimento tornam-se expressões vazias.

\section{ARTIGO INTERNACIONAL}

Dolors Palau Sampio, doutora em Jornalismo e professora na Universidade de Valência, Espanha, faz uma reflexão crítica sobre a cobertura dos conflitos internacionais a partir da obra do jornalista Ryszard Kapuscinski. Polonês, falecido em 2007, ele foi um dos maiores jornalistas do século XX. Em sua incansável atividade profissional, cobriu os principais conflitos armados depois da Segunda Guerra Mundial, inclusive a Guerra anticolonial em Angola e Moçambique. A autora toma os textos de Kapuscinski como exemplo de um jornalismo capaz de revelar os dramas e o impacto à vida humana trazidos pelos combates armados.

\section{GESTÃO DA COMUNICAÇÃO}

No artigo Encartes especiais: a gestão do conflito entre publicidade e produção gráfica, o gestor de comunicação Sergio Picciarelli Júnior relata sua experiência profissional no processo de criação e produção dos encartes publicitários, com recursos especiais veiculados pelas revistas da Editora Abril.

\section{ENTREVISTA}

Neste número, Comunicação \& Educação traz a palavra de Danilo Santos de Miranda, diretor regional do Sesc-SP, responsável direto pela política cultural de ponta incrementada pelo Sesc no estado de São Paulo. Danilo é uma figura expressiva no cenário dos profissionais gestores na área da cultura, que tem conseguido formular, com sua equipe, um trabalho de comprovada excelência.

\section{CRÍTICA}

A professora Márcia Perencin Tondato, em A tecnologia em favor da ficcionalização da violência, ou como tornar a violência atraente, faz uma reflexão crítica sobre o seriado A Lei e o Crime, produzido e veiculado pela Rede Record no início de 2009, que atingiu considerável índice de audiência, elevando com isso o número de capítulos da série. A autora tem como mote a discussão sobre a violência na programação televisiva.

\section{DEPOIMENTO}

Nesta seção, Comunicação \& Educação presta homenagem ao saudoso Prof. Osvaldo Sangiorgi, ao fazer uma síntese do seu trabalho, a partir de comentá- 
comunicação \& educação • Ano XIV • Número 2 - maio/ago 2009

rios de seus alunos e seguidores, e republicar o discurso proferido por ele na cerimônia pública de outorga do título de Professor Emérito, pela Escola de Comunicações e Artes da Universidade de São Paulo, em 14 de dezembro de 2000.

\section{EXPERIÊNCIA}

Mayra Rodrigues Gomes relata sua experiência de trabalho em sala de aula com a ferramenta wiki de escrita colaborativa. No artigo o Site wiki em sala de aula: uma experiência com hipertextualidade, ela revela dois anos de observações sobre a produção de textos feita por alunos de Jornalismo em sites wikis.

\section{POESIA}

No Brasil, as marcas do riso, do cômico, da blague estiveram sempre presentes como constituintes na formação da nacionalidade. Portanto, apreender o humor nos escritores é compreender também nossa nação e nosso contexto. É com esse argumento que Adilson Citelli e Cristine Vargas apresentam alguns poemas do gaúcho Mario Quintana, que deixou vasta obra publicada no Brasil e no exterior, compreendendo desde poesia, tradução, conto, crônica, jornalismo, até teatro.

\section{SERVIÇOS}

O Museu do Homem do Nordeste é a instituição que a seção Serviços apresenta aos leitores de Comunicação \& Educação no presente número. Vânia Brayner é autora do artigo e coordenadora-geral da Instituição. Ela nos conta como o Museu cumpre seu papel de preservar a memória e a rica cultura do homem nordestino.

\section{VIDEOGRAFIA}

Na seção Videografia, Maria Ignês Carlos Magno nos presenteia com sua proposta de leitura e discussão a partir do filme Lavoura arcaica, dirigido por Luiz Fernando Carvalho e adaptado do livro homônimo de Raduan Nassar.

\section{BOLETIM BIBLIOGRÁFICO}

A tradicional seção Boletim Bibliográfico traz sugestões de leitura na área de Comunicação e Educação, bem como estudos da ficção seriada televisiva e indicações de pesquisa em Endereços Úteis na Internet.

\section{ATIVIDADES EM SALA DE AULA}

Tomando como base os artigos deste número de Comunicação \& Educação, Ruth Ribas Itacarambi faz propostas de projetos pedagógicos a serem desenvolvidos com os alunos em sala de aula. 